\title{
Cimentos endodônticos: análise morfológica imediata e após seis meses utilizando microscopia de força atômica
}

\section{Endodontic cements: morphological analysis carried out immediately and after a six-month storage, using atomic force microscopy}

\author{
Marcia Carneiro VALERA* \\ Ana Lia ANBINDER** \\ Mário Roberto LEONARDO*** \\ Nivaldo Antônio PARIZOTO**** \\ Maurício Urban KLEINKE*****
}

\begin{abstract}
VALERA, M. C.; ANBINDER, A. L.; LEONARDO, M. R.; PARIZOTO, N. A.; KLEINKE, M. U. Cimentos endodônticos: análise morfológica imediata e após seis meses utilizando microscopia de força atômica. Pesqui Odontol Bras, v. 14, n. 3, p. 199-204, jul./set. 2000.
\end{abstract}

\begin{abstract}
O objetivo deste trabalho foi analisar a morfologia dos cimentos Sealapex, Apexit, Sealer 26 (cimentos a base de hidróxido de cálcio) e Ketac Endo (cimento de ionômero de vidro), através da microscopia de força atômica, verificando-se as características de suas partículas após a obturação dos canais radiculares e após um periodo de seis meses de contato com o plasma sanguíneo humano. Utilizaram-se 16 dentes unirradiculares humanos extraídos e incluídos em blocos de resina após o preparo biomecânico. As raízes foram divididas em quatro grupos de quatro raízes cada e os canais radiculares obturados pela técnica de condensação lateral passiva com os cimentos em estudo. Verificou-se que o cimento Apexit foi o que mais sofreu desintegração após seis meses de imersão em plasma sanguíneo humano, seguido pelo Ketac Endo e Sealapex. Dentre todos os cimentos estudados, o Sealer 26 mostrou-se o mais uniforme e com a menor desintegração.
\end{abstract}

UNITERMOS: Endodontia; Cimentos dentários; Obturação do canal radicular; Microscopia de força atômica.

\section{INTRODUÇÃO}

A obturação dos canais radiculares possui objetivos de natureza técnica, voltados à obliteração de todo o sistema de canais radiculares e também objetivos de natureza biológica, permitindo o fechamento do forame apical, por meio da deposição de tecido mineralizado por parte do organismo ${ }^{8}$. Para alcançar esses objetivos, além das técnicas de obturação, os materiais obturadores têm um papel de extrema importância. Na escolha de cimentos e pastas, deve-se sempre levar em consideração as propriedades físicas e biológicas dos materiais.

Com o desenvolvimento de métodos de aumento, baseados na emissão de íons e elétrons durante o século XX, a microscopia é atualmente capaz de permitir a análise de superfícies de materiais até o nível atômico ${ }^{4}$, o que indica o seu uso no estudo das propriedades fisicas e das partículas de cimentos endodônticos.

A microscopia de força atômica (AFM) surgiu pela primeira vez para a utilização científica no ano de 1990, e as publicações das áreas biológicas concernentes a seu uso têm aumentado. Por este método, é possivel estudar superficies de materiais além dos alcances das microscopias eletrônica e óptica, com a obtenção de imagens de macromoléculas com resolução quase atômica, e com as vantagens de praticamente não haver a necessidade de um preparo para tornar a amostra condutora, como acontece, por exemplo, na microscopia ele-

\footnotetext{
* Professora Doutora da Faculdade de Odontologia de São José dos Campos da UNESP.

** Cirurgiã-Dentista.

*** Professor Titular da Faculdade de Odontologia de Araraquara da UNESP.

**** Professor Doutor da Faculdade de Fisioterapia da UFSCAR.

***** Professor do Departamento de Física Aplicada da UNICAMP.
} 
VALERA, M. C.; ANBINDER, A. L.; LEONARDO, M. R.; PARIZOTO, N. A.; KLEINKE, M. U. Cimentos endodônticos: análise morfológica imediata e após seis meses utilizando microscopia de força atômica. Pesqui Odontol Bras, v. 14, n. 3, p. 199-204, jul./set. 2000.

trônica de varredura ou na técnica de tunelamento ${ }^{4}$.

O objetivo deste trabalho foi analisar a morfologia das partículas dos cimentos Sealapex (KerrSybron), Apexit (Vivadent Schaan-Liechenstein), Sealer 26 (Dentsply Indústria e Comércio Ltda.) cimentos a base de hidróxido de cálcio e Ketac Endo (Espe Seefeld-Oberbay - Germany) - cimento de ionômero de vidro, através da microscopia de força atômica para verificar as características de suas partículas após obturação dos canais e após um período de seis meses de contato com o plasma sanguíneo humano.

\section{MATERIAL E MÉTODOS}

Foram utilizados 16 dentes unirradiculares humanos, extraídos, pertencentes ao banco de dentes da Disciplina de Endodontia da Faculdade de Odontologia de São José dos Campos - UNESP, armazenados em solução de formalina a 10\%. Após a remoção das coroas dentais, os canais radiculares foram preparados pela técnica de instrumentação seriada a um milimetro além do forame apical até a lima tipo Kerr número 80.

Todas as raizes receberam duas marcas na superficie externa, feitas com lápis preto, sendo uma a dois milímetros aquém do ápice radicular, e a outra 1,5 milimetros acima da primeira marca (em direção ao terço cervical). Em seguida, um cone de guta-percha de calibre número 80 foi introduzido no interior dos canais radiculares até o forame apical e nivelado a este nível com uma lâmina de bisturi, de modo que, em todos os canais, o cone principal atingiu o forame apical permanecendo travado a este nível.

Todos os espécimes com os cones de guta-percha foram incluidos em resina transparente (Araldite CY 248N com endurecedor HY 951). A resina foi vertida em fôrmas individuais de silicone com formato de um cone e as raízes colocadas individualmente no interior das fôrmas até que o ápice radicular tocasse o fundo da mesma, no local correspondente ao ápice do cone. As aberturas de acesso foram deixadas livres de resina de modo a permitir acesso aos canais radiculares. Após o tempo de cura da resina, os bloquinhos contendo as raízes no seu interior apresentaram um aspecto transparente.

As raizes foram divididas em quatro grupos e os canais radiculares obturados pela técnica da condensação lateral passiva, com três cones acessórios de guta-percha e os cimentos Sealapex, Sea- ler 26, Apexit e Ketac Endo, seguida de condensação vertical. As amostras foram mantidas em câmara úmida durante 12 horas.

Os blocos foram cortados transversalmente nos locais correspondentes às marcas feitas com lápis. Para este corte, utilizou-se uma serra circular (Buehler Isomet Low Speed Saw - Buehler Ltda., apparatus for microstructures analysis) com um disco de diamante (Buehler Diamond Wafering Blade High Concentration N.O. 14-42-44) de $0,015^{\prime \prime}$ sob abundante refrigeração à água. Obtiveram-se assim dois segmentos da porção apical do bloco, sendo que apenas a secção mais cervical foi utilizada na pesquisa e constituiu-se na amostra de estudo. Os seus dois lados foram identificados como lados A e B. As amostras foram então levadas para análise no microscópio de força atômica - AFM (Nano Scope II, Scanning Tunneling Microscope. Digital Instruments Inc. Santa Bárbara. C.A.93117).

Após as análises, os segmentos foram novamente encaixados ao restante dos respectivos cones e fixados a eles com duas camadas de Araldite (Brascola S.A., Ciba-Geigy). Em seguida, toda a superficie do cone de resina foi recoberta com uma espessa camada de cera pegajosa (Herpo Produtos Dentários Ltda.), inclusive a interface resina-dente na extremidade apical, mantendo apenas o material obturador exposto (lado B).

As raízes incluídas foram então imersas individualmente em plasma sanguíneo humano, contido em tubos de ensaio estéreis. Somente o lado B entrou em contato direto com o plasma. Os tubos de ensaio foram fechados com uma rolha de algodão estéril e mantidos em estufa a $37 \pm 1^{\circ} \mathrm{C}$ e umidade relativa de $100 \%$ durante seis meses. Neste periodo, o plasma sanguíneo foi trocado semanalmente ou a cada 15 dias, em ambiente asséptico, no interior de uma câmara de fluxo laminar (VECO do Brasil).

Após seis meses, as raízes foram retiradas do plasma, as amostras de estudo foram desmembradas dos cones de resina, e os lados A e B novamente analisados, utilizando-se o AFM. A Figura 1 ilustra a metodologia utilizada. Foram feitas fotomicrografias em diferentes ampliações, verificando-se as estruturas dos materiais, bem como suas possiveis alterações com o passar do tempo.

\section{RESULTADOS Grupo experimental Sealapex}

No período inicial, após a obturação, este cimento apresentou-se com um aspecto granular com a maioria dos grãos de tamanho pequeno (ta- 
VALERA, M. C.; ANBINDER, A. L.; LEONARDO, M. R.; PARIZOTO, N. A.; KLEINKE, M. U. Cimentos endodônticos: análise morfológica imediata e após seis meses utilizando microscopia de força atômica. Pesqui Odontol Bras, v. 14, n. 3, p. 199-204, jul./set. 2000.

manho médio entre 334 e $1.307 \mathrm{~nm}$ ). Em determinadas regiões observaram-se os grãos bem próximos uns dos outros, dando a impressão de uma estrutura mais plana, além de pequenas depressões na superficie do material, que pareciam constituir a substância ligante do cimento (Figura 2A).

Após seis meses de imersão no plasma sanguíneo humano, tanto para o lado B como para o lado A, observou-se uma superficie mais lisa, ainda mantendo a característica granular, mostrando menor rugosidade, sugerindo uma alteração no tamanho médio das partículas constituintes do cimento (Figura 3A). As partículas referentes à superficie $\mathrm{B}$ passaram a ter um tamanho médio entre 116 e $215 \mathrm{~nm}$, diminuição de tamanho que também ocorreu na superficie A, em que as partículas passaram a ter um tamanho aproximadamente entre 201 e $345 \mathrm{~nm}$.

\section{Grupo experimental Apexit}

$\mathrm{Na}$ análise imediata, as imagens obtidas mostraram que este cimento era constituído de estruturas predominantemente granulares de diferentes tamanhos e irregulares, o que culminou em uma superficie também irregular (Figura 2B). A maioria das partículas deste cimento possuía granulações com tamanho médio distribuído na faixa entre 286 e $606 \mathrm{~nm}$.

Após seis meses de imersão no plasma, a superfície do lado B sofreu desintegração das partículas, impossibilitando sua análise pelo AFM. Observando-se as imagens obtidas do lado A, pôde-se verificar as alterações ocorridas na estrutura do material. Notou-se uma uniformidade maior nos tamanhos dos grãos na superficie (Figura 3B). Possivelmente, os grãos mais salientes tenham se solubilizado, o que determinou uma superficie mais regular. O tamanho médio das partículas variou entre 90,6 e $189 \mathrm{~nm}$.

\section{Grupo experimental Sealer 26}

As imagens obtidas da superficie deste cimento no periodo inicial mostraram que o cimento é constituído de uma estrutura granular e homogênea (Figura 2C). As medidas das partículas deste cimento mostraram granulações com tamanho médio entre 193 e $324 \mathrm{~nm}$.

Após seis meses de imersão no plasma sanguíneo humano, verificou-se pouca alteração na superficie do Sealer 26 (Figura 3C), sendo que essas alterações não ocorreram no lado A. Em alguns pontos, observaram-se áreas de solubilização e grãos com maior irregularidade. Também, o tamanho médio destas granulações foi um pouco maior (entre 390 e $650 \mathrm{~nm}$ ) quando comparado ao período inicial.

\section{Grupo experimental Ketac Endo}

As imagens obtidas da superficie deste cimento no período inicial evidenciaram um material constituído de pequenas granulações esféricas e uniformes (Figura 2D), com poucas partículas mais salientes (tamanho médio entre 73 e 135 nm).

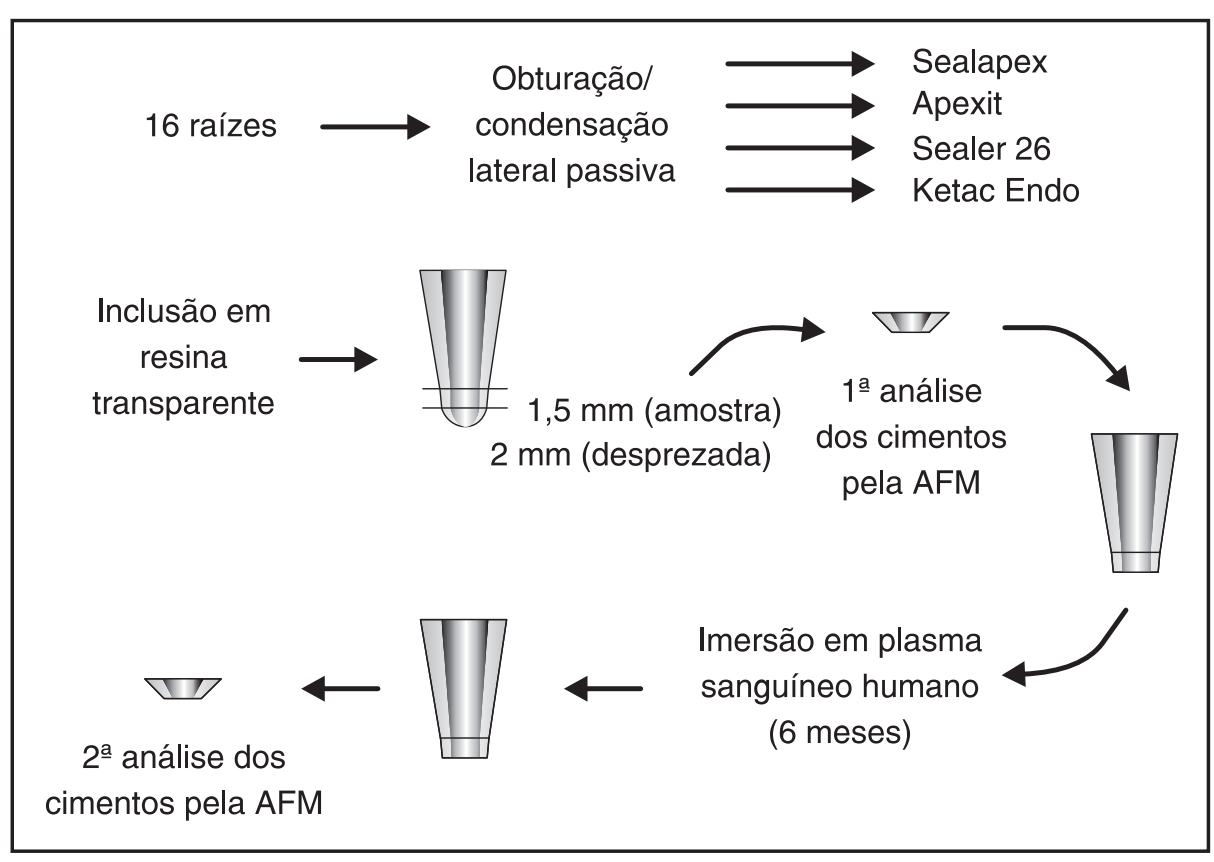

FIGURA 1 - Representação esquemática da metodologia utilizada para a análise com o AFM. 
VALERA, M. C.; ANBINDER, A. L.; LEONARDO, M. R.; PARIZOTO, N. A.; KLEINKE, M. U. Cimentos endodônticos: análise morfológica imediata e após seis meses utilizando microscopia de força atômica. Pesqui Odontol Bras, v. 14, n. 3, p. 199-204, jul./set. 2000.
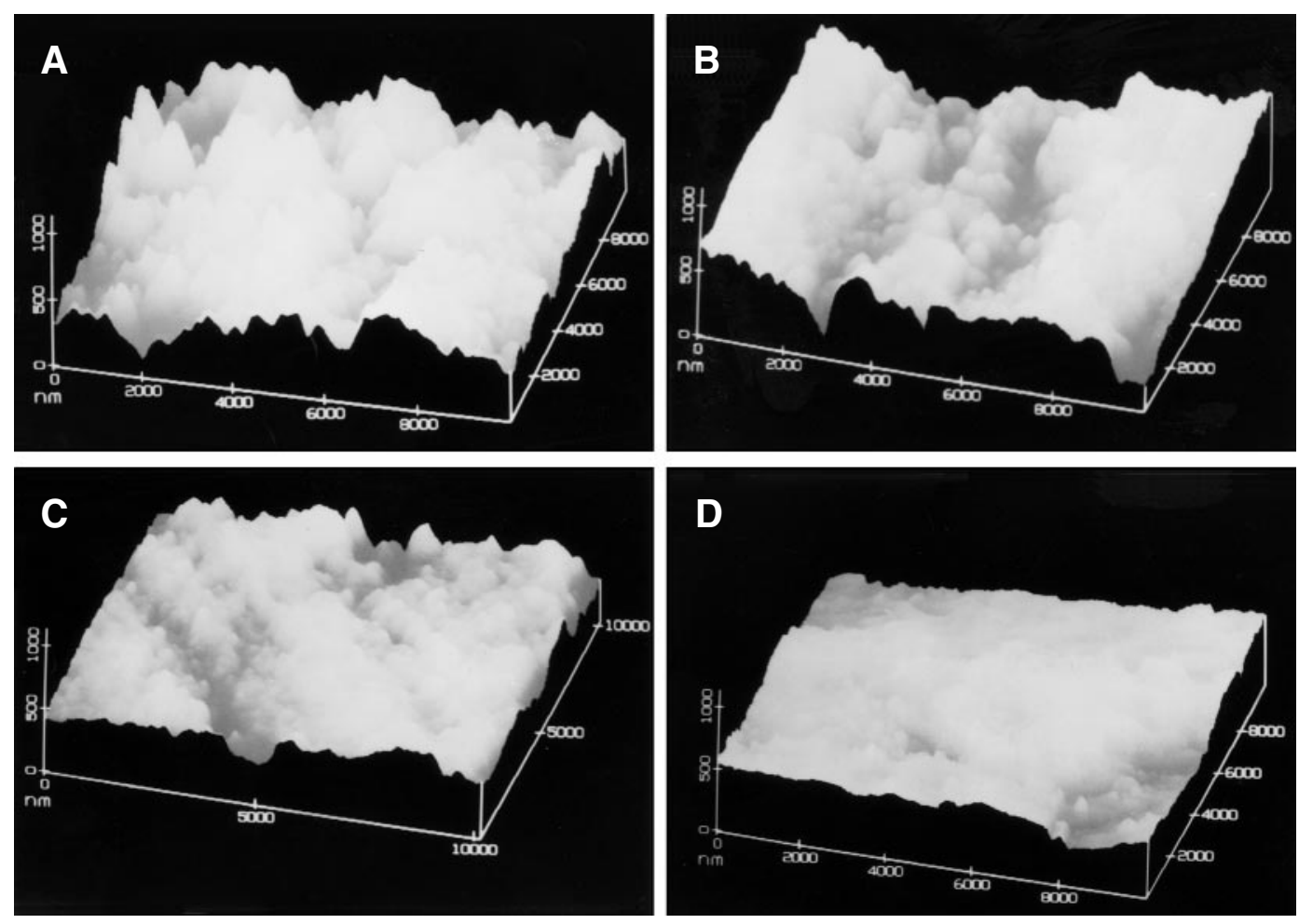

FIGURA 2 - Superficie dos cimentos após a obturação dos canais radiculares.

Fotomicrografia pelo AFM. Aumento de 8.400 X. A- Sealapex; B- Apexit; C- Sealer 26; D- Ketac Endo.

Decorridos seis meses de manutenção no plasma sanguíneo, o lado B apresentou-se bastante irregular (Figura 3D). Foi possivel a visualização de uma maior depressão entre as partículas granulares que possuíam tamanho médio entre 37,8 e $71 \mathrm{~nm}$. Estas alterações caminharam até a superficie correspondente ao lado A, que mostrou maior irregularidade mesmo não tendo entrado em contato direto com o plasma sanguíneo humano. A maioria dos grãos possuía um tamanho médio entre 22,9 e $55 \mathrm{~nm}$.

\section{DISCUSSÃO}

$\mathrm{Na}$ análise imediata do cimento Sealapex, evidenciou-se a presença de pequenos grãos contornados por uma estrutura que provavelmente correspondia à matriz do cimento. Os locais mais profundos observados nessa superficie podem ter favorecido o acúmulo do plasma sanguíneo que aí infiltrado deslocou as partículas de cimento provocando uma diminuição da rugosidade superficial. Estas alterações caminharam até o lado A. Provavelmente, estas alterações podem dar-se em niveis mais profundos, tanto para o cimento Sealapex como para os demais cimentos estudados. PE$\operatorname{TERS}^{10}$ (1986), numa análise semelhante utilizando microscopia óptica realizou cortes em quatro níveis $(1,5 ; 2,3 ; 4$ e $6 \mathrm{~mm})$ e avaliou a solubilização após dois anos do cimento Procosol e da guta-percha. Observou que as alterações caminham em direção cervical, podendo atingir uma extensão de até $4 \mathrm{~mm}$.

Já as áreas de maior regularidade, após a obturação e decorridos seis meses, sugerem ser locais menos propensos à desintegração, pois dificultam o acúmulo de substâncias fluidas. Após o período de armazenamento no plasma, a superfície do material atingiu uma característica mais uniforme, sugerindo que a desintegração sofrida pelo cimento possa ter diminuído ou até mesmo estacionado.

O trabalho de CAICEDO; VON FRAUNHOFER ${ }^{3}$ (1988) avaliou as características do Sealapex utilizando a microscopia eletrônica de varredura. Observaram que, quando esse cimento entrava em contato com a umidade durante o endurecimento, havia expansão do material, que foi atribuída à sua capacidade da absorção de água. KAZEMI et al. ${ }^{6}$ (1993) sugerem que a água absorvida leva a uma degradação dos cimentos e WU et al. ${ }^{15}$ (1995) concluíram que o Sealapex foi o cimento que mais apresentou infiltração após um ano de armazenamento em água, quando comparado ao AH 26, Ketac Endo e Tubli-seal.

No entanto, a solubilidade com elevação do $\mathrm{pH}$ pode ser benéfica, pois de acordo com LEONARDO ${ }^{8}$ (1992) é possivel que esses fatores isoladamente 
VALERA, M. C.; ANBINDER, A. L.; LEONARDO, M. R.; PARIZOTO, N. A.; KLEINKE, M. U. Cimentos endodônticos: análise morfológica imediata e após seis meses utilizando microscopia de força atômica. Pesqui Odontol Bras, v. 14, n. 3, p. 199-204, jul./set. 2000.

ou em interação com algum componente dos cimentos à base de hidróxido de cálcio possam estimular as células mesenquimais do periodonto apical a se diferenciar ou a estimularem a deposição de tecido mineralizado na região apical. BEZERRA da SILVA et al. ${ }^{1}$ (1997) comparando o Sealapex com os cimentos CRCS, Apexit e Sealer 26, encontrou no primeiro o maior pH e concentração de íons cálcio. Analisando, em dentes de cães, os cimentos Sealapex e Fill Canal, TANOMARU FILHO et al. ${ }^{12}$ (1998) encontraram o melhor selamento apical nos dentes em que se utilizou o cimento de hidróxido de cálcio.

Numa análise comparativa do Apexit com o Sealapex, pode-se também observar uma grande irregularidade na superficie do Apexit. As grandes depressões vistas na superficie deste cimento, aliadas à irregularidade das suas partículas, provavelmente facilitaram a estagnação de plasma sanguíneo com conseqüente desintegração do Apexit. Esta desintegração foi tão acentuada que, após seis meses, não foi possivel analisar a superficie que permaneceu em contato direto com o plasma sanguíneo humano. Estas alterações caminharam até o lado A, provocando uma perda de integridade visivel também nessa superficie, o que sugere ainda a continuação das alterações sofridas com o tempo. Tais alterações explicam a intensidade das respostas inflamatórias ocorridas com este cimen- to no trabalho de VALERA ${ }^{13}$ (1995) e seus pobres resultados quanto ao selamento apical ${ }^{14}$.

Já o cimento Ketac Endo mostrou um comportamento quase inverso ao dos demais cimentos. No periodo inicial, verificou-se regularidade no tamanho das partículas com poucos pontos que pudessem acumular fluidos. Apesar disto, após seis meses, houve um aumento da irregularidade de sua superficie, demonstrando uma contínua desintegração deste cimento. Provavelmente, isto se deva à pobre matriz formada durante seu endurecimento. HORNING; KESSLER ${ }^{5}$ (1995) estudando o efeito da umidade sobre o Ketac Endo, dizem que no período inicial de endurecimento do cimento, partículas de vidro que não reagiram ficam rodeadas por um gel de sílica e uma matriz amorfa de polissais de alumínio e cálcio. Com a umidade, os cátions que formam a matriz podem ser dissolvidos inibindo a formação de polissais de alumínio necessários para seu endurecimento final, levando ao enfraquecimento do cimento. É provável que essa reação possa explicar as grandes alterações observadas.

\section{CONCLUSÕES}

Considerando-se as avaliações realizadas na metodologia proposta, verificou-se que:

- o contato com o plasma sanguíneo humano provocou alterações na estrutura dos cimentos;
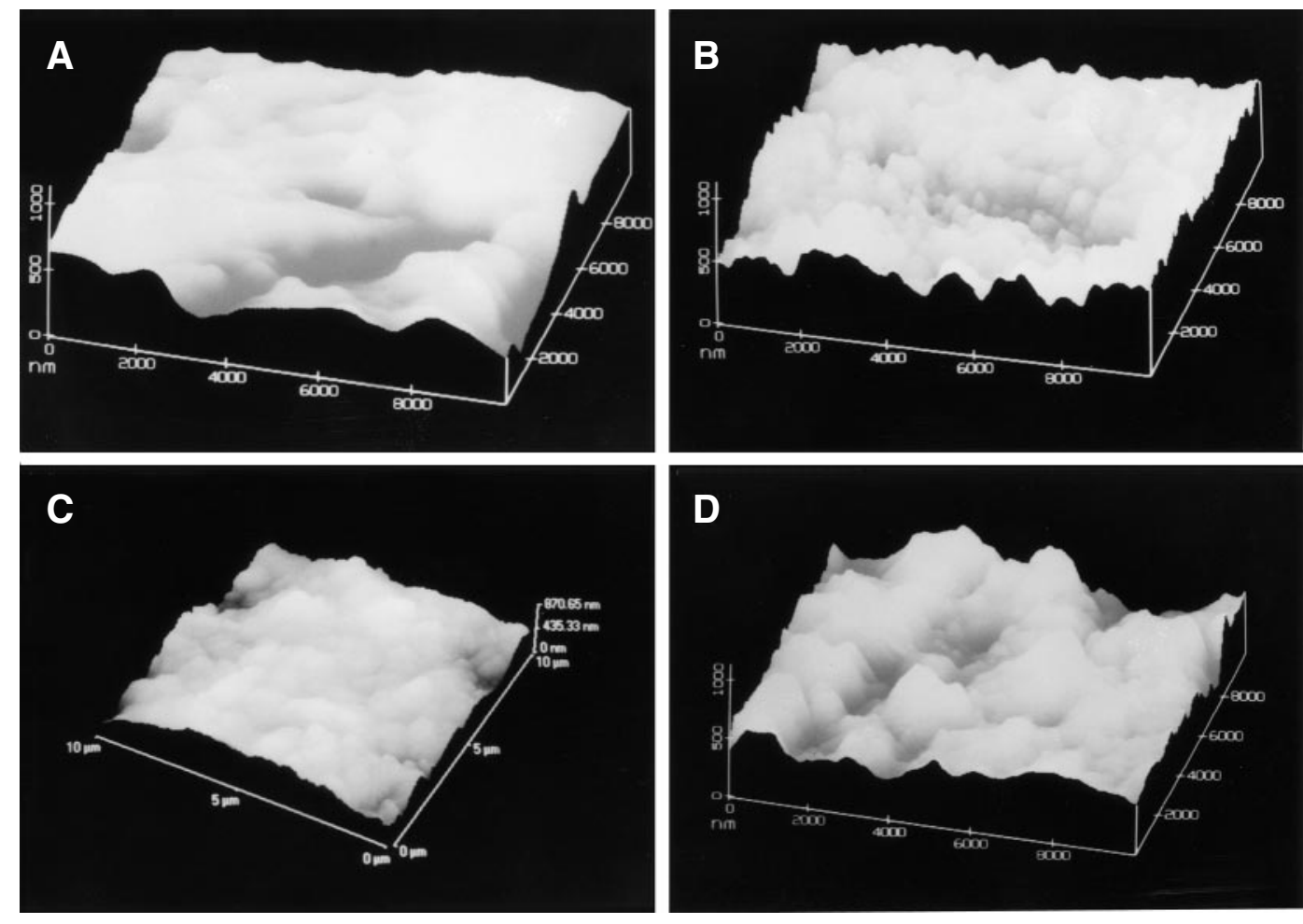

FIGURA 3 - Superficie dos cimentos após seis meses de manutenção em plasma sanguineo. Fotomicrografia pelo AFM. Aumento de 8.400 X. A- Sealapex (superficie B); B- Apexit (superficie A); C- Sealer 26 (superficie B); DKetac Endo (superficie B). 
VALERA, M. C.; ANBINDER, A. L.; LEONARDO, M. R.; PARIZOTO, N. A.; KLEINKE, M. U. Cimentos endodônticos: análise morfológica imediata e após seis meses utilizando microscopia de força atômica. Pesqui Odontol Bras, v. 14, n. 3, p. 199-204, jul./set. 2000.

- o Sealer 26 apresentou desintegração mínima após seis meses de contato com o plasma sanguíneo humano;
- de todos os cimentos estudados, o Apexit apresentou a maior perda de estrutura, seguido pelo Ketac Endo e Sealapex.

VALERA, M. C; ANBINDER, A. L.; LEONARDO, M. R.; PARIZOTO, N. A.; KLEINKE, M. U. Endodontic cements: morphological analysis carried out immediately and after a six-month storage, using atomic force microscopy. Pesqui Odontol Bras, v. 14, n. 3, p. 199-204, jul./set. 2000.

The aim of this study was to analyze the high resolution morphological characteristics of Sealapex, Apexit, Sealer 26 (calcium hydroxide cements) and Ketac Endo (glass ionomer cement), using atomic force microscopy (AFM), immediately after root canal obturation and six months after it, keeping the roots stored in human blood plasma. The AFM evaluation used 16 single-rooted human teeth embedded in resin blocks after biomechanical preparation. The samples were divided into four groups (four roots each) and the passive lateral condensation filling technique was used in the obturation of the canals with the mentioned sealers. Apexit suffered the highest degree of disintegration after the six-month storage in human blood plasma, followed by Ketac Endo and Sealapex. Sealer 26 was the most uniform cement and suffered the least disintegration.

UNITERMS: Endodontics; Dental cements; Root canal obturation; Microscopy, atomic force.

\section{REFERÊNCIAS BIBLIOGRÁFICAS}

1. BEZERRA da SILVA, L. A.; LEONARDO, M. R.; DA SILVA, R. S.; ASSED, S.; GUIMARÃES, L. F. L. Calcium hydroxide root canal sealers: evaluation of $\mathrm{pH}$, calcium ion concentration and conductivity. Int Endod J, v. 30, n. 3, p. 205-209, May 1997.

2. BIRREL, G. B.; HEDBERG, K. K.; HABLISTON, D. L.; GRIFFITH, O. H. Biological applications of photoelectron imaging: a pratical perspective. Ultramicroscopy, v. 36, n. 1-3, p. 235-251, May 1991.

3. CAICEDO, R.; VON FRAUNHOFER, J. A. The properties of endodontic sealer cements. J Endod, v. 14, n. 11, p. 527-534, Nov. 1988.

4. EDSTROM, R. D.; MEINKE, M. H.; YANG, X.; YANG, R.; EVANS, D. F. Scanning tunneling microscopy of the enzymes of muscle glycogenolisis. Ultramicroscopy, v. 33, n. 2, p. 99-106, Aug. 1990.

5. HORNING, T. G.; KESSLER, J. R. A comparison of three different root canal sealers when used to obturate a moisture-contaminated root canal system. J Endod, v. 21, n. 7, p. 354-357, July 1995.

6. KAZEMI, R. B.; SAFAVI, K. E.; SPANGBERG, L. S. W. Dimensional changes of endodontic sealers. Oral Surg Oral Med Oral Pathol, v. 76, n. 6, p. 766-771, Dec. 1993.

7. LEONARDO, M. R.; LEAL, J. M. Endodontia: tratamento dos canais radiculares. 3. ed. São Paulo : Panamericana, 1998. 902 p.

8. LEONARDO, R. T. Avaliação microscópica de reação apical e periapical frente a dois cimentos obturadores de canais radiculares a base de hidróxido de cálcio (CRCS e Sealapex) em dentes de cães. Bauru, 1992. 104 p. Dissertação (Mestrado em Endodontia) -
Faculdade de Odontologia de Bauru, Universidade de São Paulo.

9. MORRIS, V. J. Biological applications of scanning probe microscopes. Prog Biophys Molec Biol, v. 61, n. 2, p. 131-185, Dec. 1994.

10. PETERS, D. D. Two-year in vitro solubility evaluation of four gutta-percha sealer obturation techniques. $\mathbf{J}$ Endod, v. 12, n. 4, p. 139-145, Apr. 1986.

11. STEMMER, A.; ENGEL, A. Imaging biological macromolecules by STM: quantitative interpretation of topographs. Ultramicroscopy, v. 34, n. 3, p. 129-140, Dec. 1990.

12. TANOMARU FILHO, M.; LEONARDO, M. R.; SILVA, L. A. B.; UTRILLA, L. S. Effect of different root canal sealers on periapical repair of teeth with chronic periradicular periodontitis. Int Endod J, v. 31, n. 2, p. 85-89, Mar. 1998.

13. VALERA, M. C. Estudo da compatibilidade biológica de alguns cimentos à base de hidróxido de cálcio e um cimento de ionômero de vidro. Avaliação do selamento marginal apical e análise morfológica por microscopia de força atômica. Araraquara, 1995. 333 p. Tese (Doutorado) - Faculdade de Odontologia de Araraquara, Universidade Estadual Paulista "Júlio de Mesquita Filho".

14. VALERA, M. C.; LEONARDO, M. R.; BONETTI FILHO, I. Cimentos endodônticos - selamento marginal apical imediato e após armazenamento de seis meses. Rev Odontol Univ São Paulo, v. 12, n. 4, p. 355-360, out./dez. 1998.

15. WU, M. K; WESSELING, P. R.; BOERSMA, J. A 1-year follow-up study on the leakage of four root canal sealers at different thicknesses. Int Endod J, v. 28, n. 4, p. 185-189, July 1995.
Recebido para publicação em 01/09/99 Enviado para reformulação em 18/05/00 Aceito para publicação em 14/06/00 